\title{
Contribuições para elaboração de um Guia de Avaliação Institucional
}

\author{
Fabiana Centeno Fagundes \\ Instituto Federal Sul-rio-grandense (IFSul) - Campus Gravataí \\ Instituto Federal do Rio Grande do Sul (IFRS) - Campus Porto Alegre \\ (fabianacenteno@ifsul.edu.br) \\ Clarice Monteiro Escott \\ Instituto Federal do Rio Grande do Sul (IFRS) - Campus Porto Alegre \\ (clarice.escott@poa.ifrs.edu.br)
}

\begin{abstract}
Resumo: Este artigo apresenta parte da pesquisa "Avaliação Institucional: Contribuições Para A Qualidade dos Processos de Gestão do Ensino Técnico e Tecnológico" que está sendo desenvolvida no Programa de Mestrado Profissional em Educação Profissional (PROFEPT), no IFRS. Essa pesquisa pretende desenvolver um produto educacional que possa contribuir para o fortalecimento $\mathrm{e}$ a articulação da Avaliação Institucional com os processos institucionais de gestão, articulado ao planejamento participativo no IFSul - campus Gravataí. Especificamente, neste trabalho é apresentado o referencial teórico e os resultados parciais obtidos a partir da análise documental. A questão de pesquisa surgiu a partir das experiências como representante da CPA do IFSul, o que possibilitou verificar algumas fragilidades no processo. A revisão teórica se sustenta em autores como Dias Sobrinho $(2003,2008,2010)$ para Avaliação Institucional, Leite (2005) na perspectiva da Avaliação Participativa e Saul (2003) com o conceito de Avaliação Emancipatória. Assim como em Lück (2010), Dalmás (2011), Libâneo (2008) e Paro (2008), para a análise sobre a gestão educacional e planejamento participativo. A metodologia consistiu em um mapeamento de materiais com o propósito de identificar a existência de produtos semelhantes ao proposto na pesquisa, como cartilhas/manuais de avaliação. A partir da análise realizada em publicações de Universidades e Institutos Federais, verificou-se que os resultados apontavam para o avanço no modelo proposto como produto dessa pesquisa em relação às práticas existentes, visto que essas instituições devem promover a democratização dos processos. A partir do entendimento de que é fundamental investir na produção de pesquisa e na elaboração de um produto educacional que estimule o alinhamento entre avaliação, gestão democrática e planejamento participativo. Ao olhar o processo de avaliação institucional com mais atenção, reforça-se a importância da melhoria da qualidade da educação oferecida pela Instituição, em todos os níveis e funções. Esta pesquisa visa contribuir para a melhoria dos processos de avaliação institucional e de gestão participativa do IFSul e poderá ser utilizada por outros campi do respectivo instituto, bem como por outros Institutos Federais, além de apontar caminhos possíveis para fortalecer a cultura da avaliação Institucional alinhada às particularidades da institucionalidade dos Institutos Federais.
\end{abstract}

Palavras-chave: Avaliação Institucional; Gestão Democrática; Planejamento Participativo; Avaliação Emancipatória.

\section{Contributions to the elaboration of an Institutional Evaluation Guide.}

Abstract: This paper presents part of the research "Institutional Evaluation: Contributions to the Quality of Management Processes of Technical and Technological Education" that is being developed in the Professional Master's Program in Professional Education (PROFEPT), at IFRS. This research aims to develop an educational product that can contribute to the strengthening and articulation of Institutional Evaluation with institutional management processes, articulated to participatory planning at IFSul - campus Gravataí. Specifically, this paper presents the theoretical framework and partial results obtained from documentary analysis. The research question arose from experiences as representative of the IFSul CPA, which made it possible to verify some weaknesses in the process. The theoretical review is supported by authors such as Dias Sobrinho $(2003,2008,2010)$ for Institutional Evaluation, Leite (2005) from the perspective of Participatory Evaluation and Saul (2003) with the concept of Emancipatory Evaluation. As in Lück (2010), Dalmás (2011), Libâneo (2008) and Paro (2008), for the analysis of educational management and participatory planning. The methodology consisted of a mapping of materials in order to identify the existence of products similar to those proposed in the research, such as booklets / evaluation manuals. From the analysis performed in 
publications from Federal Universities and Institutes, it was found that the results pointed to the advance in the proposed model as a product of this research in relation to existing practices, since these institutions should promote the democratization of processes. From the understanding that it is essential to invest in research production and in the elaboration of an educational product that stimulates the alignment between evaluation, democratic management and participatory planning. Taking a closer look at the institutional evaluation process reinforces the importance of improving the quality of education offered by the institution at all levels and functions. This research aims to contribute to the improvement of the institutional evaluation processes and participatory management of IFSul and may be used by other campuses of the respective institute, as well as by other Federal Institutes, as well as pointing possible ways to strengthen the culture of institutional evaluation aligned with particularities of the institutionality of the Federal Institutes institucional evaluation aligned with particularities of the institutionality of the Federal Institutes.

Keywords: Institutional Evaluation, Democratic Management, Participatory Planning, Emancipatory Evaluation.

\section{INTRODUÇÃO}

Este artigo apresenta parte da pesquisa que está sendo desenvolvida no Programa de Mestrado Profissional em Educação Profissional (PROFEPT), no IFRS. Com o desenvolvimento da investigação, pretende-se desenvolver um produto educacional que possa contribuir para o fortalecimento e a articulação da Avaliação Institucional com os processos institucionais de gestão, articulado ao planejamento participativo no IFSul - campus Gravataí. Nesse trabalho apresento os resultados parciais obtidos na análise documental.

Conforme definido pela LDB (Lei 9394/96), a União incumbir-se-á de: assegurar processo nacional de avaliação do rendimento escolar no ensino fundamental, médio e superior, em colaboração com os sistemas de ensino, objetivando a definição de prioridades e a melhoria da qualidade de ensino, além de assegurar processo nacional de avaliação das instituições de ensino superior, com cooperação dos sistemas que tiverem responsabilidade sobre este tipo de oferta. No entanto, no âmbito do MEC não existem políticas de avaliação que considerem a complexidade do modelo de institucionalidade dos Institutos Federais.

Com relação à avaliação da Educação Superior, para atender a essa normativa foi criada a Lei $n^{\circ} 10.861$, de 14 de abril de 2004, que instituiu o SINAES, que tem por finalidade a melhoria da qualidade da educação superior, a orientação da expansão da sua oferta, o aumento permanente da sua eficácia institucional e efetividade acadêmica e social e, especialmente, a promoção do aprofundamento dos compromissos e responsabilidades sociais das instituições de educação superior, por meio da valorização de sua missão pública, da promoção dos valores 
democráticos, do respeito à diferença e à diversidade, da afirmação da autonomia e da identidade institucional.

Os Institutos Federais são a concretização da política pública definida pela Lei $N^{0} 11.892$, de 29 de dezembro de 2008, e estão voltados para a oferta de educação profissional técnica e tecnológica no Brasil. O referido documento legal indica que, a cada exercício, essas instituições devem garantir o mínimo de 50\% (cinquenta por cento) de suas vagas para atender cursos de nível médio, preferencialmente integrados, e o mínimo de $20 \%$ (vinte por cento) de suas vagas para licenciaturas. Destaca-se que o Decreto $N^{\circ} 5.840$, de 13 de julho de 2006, já orienta as instituições federais de educação profissional a disponibilizarem no mínimo dez por cento do total das vagas de ingresso da instituição para Programa Nacional de Integração da Educação Profissional à Educação Básica na Modalidade de Educação de Jovens e Adultos (PROEJA).

Nos Institutos Federais, assim como em outras instituições que oferecem a educação superior, o processo de autoavaliação deve ser conduzido por uma Comissão Própria de Avaliação (CPA). Em 2017, foi publicada a Portaria IFSul nº 3009/2017, de 06 de novembro de 2017, que designa os servidores e discentes para constituírem a $1^{\text {a }}$ Comissão Própria do campus Gravataí, da qual faço parte e cujo trabalho motivou a elaboração dessa pesquisa. No entanto, é possível perceber que essa comissão foi criada com intuito de atender as exigências da Reitoria/CPA Central, em vez de suprir uma necessidade interna de avaliação dos cursos.

Ao longo dessa experiência na Comissão Própria de Avaliação (CPA), percebo uma fragilidade entre os processos de avaliação institucional, seus resultados e o planejamento de gestão. Entendo que os processos avaliativos devem contribuir diretamente para subsidiar as tomadas de decisão da gestão e a qualidade do trabalho desenvolvido numa instituição de ensino, superando a centralização e as decisões unilaterais. Segundo Lück (2011, p. 15):

O movimento de democratização concentra-se em três vertentes básicas da gestão escolar: a) participação da comunidade escolar na seleção dos gestores da escola; b) criação de um colegiado/conselho escolar que tenha tanto autoridade deliberativa como poder decisório e c) repasse de recursos financeiros às escolas, e, consequentemente, aumento de sua autonomia.

"Para garantir a existência de tempo e recursos suficientes voltados para a 
participação, faz-se necessária a capacitação dos integrantes da comunidade escolar (professores, gestores, pais e alunos). Preparar a comunidade escolar para a gestão democrática é a essência da transformação do sistema de ensino". (LÜCK et al., 2011. p. 30). Assim, como destaca Libâneo (2008, p.143), “a organização escolar democrática implica não só a participação na gestão, mas a gestão da participação".

As políticas de avaliação Institucional estão interligadas com as mudanças políticas e econômicas vigentes no país. Aqui, destaco alguns marcos históricos da Avaliação Institucional no Brasil, em andamento a partir da década de 1930. Esse processo foi interrompido pelo momento político-militar de 1964 e retomado em 1975, com a implantação do sistema de avaliação dos cursos de pós-graduação pela CAPES.

$\mathrm{Na}$ década de 1980, a mais relevante experiência de sistematização da avaliação foi apresentada no Programa de Avaliação da Reforma Universitária (PARU), desenvolvida pelo governo militar e tinha por objetivo conhecer as condições do Sistema de Educação Superior, ao questionar as questões de qualidade de ensino, relação da pesquisa com ensino, extensão e prestação de serviços à comunidade e atividades administrativas. De acordo com Barreyo e Rothen (2007, p. 135) uma das "heranças deixadas pelo programa foi a sua preocupação com a avaliação dos resultados da Gestão das Instituições de Educação Superior. No contexto do PARU, a ênfase nos processos de gestão não significou a desvalorização dos procedimentos acadêmicos, mas a incorporação dessa dimensão na análise institucional". Esse programa não chegou a apresentar seus resultados porque foi desativado um ano depois de ter começado.

Em 1983, foi criado o Projeto de Avaliação de Reforma Universitária. Na década de 1990, a Andifes lançou a Proposta Nacional de Avaliação, que institucionalizou o Programa de Avaliação Institucional das Universidades Brasileiras (PAIUB), projeto centrado na graduação, com objetivo de apoiar técnica e financeiramente os processos de avaliação da IES. O PAIUB estava orientado pelos seguintes princípios: globalidade, comparabilidade, respeito à identidade institucional, não premiação e punição, adesão voluntária, legitimidade e continuidade. Esse Programa era composto de três fases: avaliação interna, avaliação externa e reavaliação. 
Apesar de o PAIUB ter considerado a realidade de cada IES na construção de suas respectivas culturas avaliativas e nos mecanismos de autoavaliação institucional, ainda assim, privilegiava indicadores quantitativos de análise, concedendo financiamentos somente aos projetos que pudessem abranger os índices de eficácia estipulados pelo Estado. (SOUZA, 2002, p. 312).

O Decreto N ${ }^{\circ}$ 2026/96, instituído pelo governo Fernando Henrique Cardoso, diferentemente do que propunha o PAIUB, estabelecia, de forma autoritária, os procedimentos para o processo de avaliação externa de cursos e instituições superiores, e priorizava a avaliação dos seguintes indicadores: taxas de escolarização bruta e líquida, taxas de disponibilidade e de utilização de vagas para ingressantes, taxas de evasão e de produtividade, tempo médio para a conclusão dos cursos, índices de qualificação do corpo docente, tamanho médio das turmas, participação da despesa com ensino superior nas despesas públicas com educação, despesas públicas por aluno no ensino superior público, despesa por aluno em relação ao PIB por habitante nos sistemas público e privado, proporção da despesa pública com a remuneração de professores. Segundo Dias Sobrinho (2010, p. 204), "esse documento foi elaborado sob inspiração do modelo proposto pela OCDE e sob impacto da globalização econômica e a ampla hegemonia ao neoliberalismo", o que explica a preocupação em verificar se o peso dos gastos econômicos com educação atendia as expectativas governamentais de bom funcionamento das instituições públicas em comparação com o setor privado.

Nessa conjuntura, ficou popularizado o "Provão", oficialmente denominado Exame Nacional de Cursos (ENC), de presença obrigatória para os concluintes dos cursos superiores. Nesse período, boa parte da sociedade acrítica contribuiu para "consolidar o Provão como instrumento de regulação e de informação do setor educativo de nível superior" (DIAS SOBRINHO, 2010, p. 204-205), reduzindo a avaliação a um único instrumento.

Esses fatores levaram ao surgimento do "mercado" como uma possível solução para estes problemas e, inevitavelmente, disseram que a autonomia das universidades deveria ser acompanhada por uma prestação de contas, como meio de demonstrar para a sociedade que o dinheiro público foi bem gasto. E essa prestação de contas estava, obviamente, ligada à avaliação da qualidade. Consequentemente, a avaliação da qualidade assumiu duas direções (e objetivos contraditórios): melhoria da qualidade (ensino superior) e prestação de contas (das instituições de ensino superior); o primeiro objetivo é essencialmente perseguido pelos acadêmicos e 
instituições de ensino superior e, o segundo, por governos. (AMARAL, 2009, p. 14)

Determinar fundamentalmente a qualidade da educação por métodos classificatórios não representa os objetivos de uma Avaliação Institucional de cunho educativo, pelo contrário, "como efeito pedagógico, os testes nacionais e classificadores têm tido uma função muito mais de disciplina e modelação que diagnóstico com intencionalidade formativa" (DIAS SOBRINHO, 2003, p. 156). Esses métodos priorizam a competitividade individual ao invés dos valores coletivos, de colegialidade, de solidariedade e de democracia.

$\mathrm{Na}$ década seguinte, o SINAES surgiu como uma proposta dentro das políticas de avaliação que se construíam considerando a avaliação interna e externa. Esse Sistema foi instituído pela Lei $\mathrm{n}^{\circ} 10.861 / 2004$, com o objetivo de assegurar o processo nacional de avaliação das instituições de educação superior, dos cursos de graduação e do desempenho acadêmico de seus estudantes, garantindo um olhar amplo sobre as instituições. O SINAES tem por finalidade a melhoria da qualidade da educação superior, a orientação da expansão da sua oferta, o aumento permanente da sua eficácia institucional e efetividade acadêmica e social e, especialmente, a promoção do aprofundamento dos compromissos e responsabilidades sociais das instituições de educação superior, por meio da valorização de sua missão pública, da promoção dos valores democráticos, do respeito à diferença e à diversidade, da afirmação da autonomia e da identidade institucional.

$\mathrm{Na}$ avaliação assim concebida pelo SINAES, são as "próprias instituições que se autoavaliam a partir do seu modelo institucional, sua missão e sua realidade" (LEITE, 2005, p. 65). Para conduzir o processo de autoavaliação institucional, cada IES deve assegurar a composição de uma CPA.

De acordo com as Orientações Gerais para o Roteiro de Autoavaliação das Instituições (2004), cada instituição de Ensino Superior deve realizar uma autoavaliação, que será o primeiro instrumento a ser incorporado ao conjunto de mecanismos constitutivos do processo global de regulação e avaliação. Para conduzir esse processo a primeira etapa consiste na composição de uma CPA, que irá fazer a seleção dos indicadores adequados à sua IES. 
CPA deve contar, na sua composição, com a participação de representantes de todos os segmentos da comunidade universitária e, também, da sociedade civil organizada. As definições quanto à quantidade de membros, forma de composição, duração do mandato, dinâmica de funcionamento e modo de organização das CPAs serão objeto de regulação própria e aprovadas pelo órgão colegiado máximo da instituição (BRASIL. MEC/CONAES/INEP, 2004, p. 9)

Na estrutura administrativa, as CPAs têm a prerrogativa de autonomia, já que são entendidas como órgãos de representação acadêmica e não de administração da instituição. No entanto, elas enfrentam a dificuldade de reunir, e ter participação efetiva, dos servidores dos diversos campi e, por não ter um setor de suporte técnico, dependem das demais estruturas do Instituto.

Além da autoavaliação conduzida pela CPA, o SINAES prevê outros instrumentos complementares para avaliar a qualidade dos cursos oferecidos na IES, são eles: avaliação externa, ENADE e avaliação dos cursos de graduação, que juntos compõem o tripé da avaliação proposto pelo SINAES (figura 1). Além disso, as instituições devem considerar as informações provindas do Censo e do Cadastro.

A Avaliação das Instituições de Educação Superior é organizada em duas etapas principais, sendo uma a autoavaliação conduzida pela CPA e a outra a avaliação externa, realizada por comissões designadas pelo Instituto Nacional de Estudos e Pesquisas Educacionais Anísio Teixeira (INEP). Essas avaliações são conduzidas com base em um documento orientador que

apresenta os princípios balizadores de sua proposta: respeito às peculiaridades históricas e características institucionais de cada IES; observação da missão e do processo de auto-avaliação da instituição como pontos de partida e elementos fundamentais da avaliação realizada por pares externos; realização de um adequado processo de auto-avaliação, com identificação das potencialidades e fragilidades de cada IES, com a finalidade de desenvolver projetos voltados à melhoria da qualidade acadêmica; constante manutenção do processo de auto-avaliação, com a assimilação das recomendações resultantes do processo de avaliação externa; elaboração de relatório de avaliação externa que sirva como referencial básico para o aperfeiçoamento da instituição, que ofereça subsídios para o aperfeiçoamento da política de educação superior e que forneça elementos para os processos regulatórios do sistema educativo. (ESCOTT, 2008, p. 111).

O Exame Nacional de Desempenho de Estudantes (ENADE) aplica-se aos concluintes dos cursos de graduação e é de caráter obrigatório. A definição das áreas participantes é estabelecida anualmente, por procedimentos amostrais, e a 
periodicidade máxima da avaliação é trienal para cada área do conhecimento.

A regulação dos cursos de graduação prevê que eles sejam avaliados periodicamente por meio de instrumentos e metodologia que incluem visitas de comissões externas. Os cursos de educação superior passam por três tipos de avaliação: para autorização, para reconhecimento e para renovação de reconhecimento ${ }^{1}$.

Como forma de orientar os procedimentos para elaboração dos instrumentos e os procedimentos para a condução do processo de avaliação externa e autoavaliação da instituição, o SINAES dispunha de 10 dimensões. Em 2014, essas foram reorganizadas em cinco eixos avaliativos

Ao tomar para si o processo, a instituição garante sua autonomia. Dito de outra forma, anula-se a possibilidade de que as regulamentações fabricadas externamente e impostas pelos governos de forma burocrática e autoritária sejam os condutores dos processos nas IES. Nas palavras de Dias Sobrinho (2008b), buscase reforçar um conceito de regulação que

dialoga com a autonomia, isto é, com a promoção dos possíveis, a invenção de caminhos e a projeção dos horizontes próprios. A autonomia não se confunde com a soberania, está sempre em relação com a alteridade e, portanto, com a heteronomia. Enquanto a regularização como mera conformação à norma e aos regulamentos é uma abdicação da autonomia, a regulação é um processo que faz intervir o diálogo ou a relação entre a autonomia, que é o exercício criativo e crítico da auto-regulação, e o quadro normativo externo, isso é, a heteronomia. (DIAS SOBRINHO, 2008b, p. 204)

Assim, direcionando-se para uma avaliação educativa, que prioriza a melhoria e a qualidade, é questionado o papel de Estado avaliador como única referência que define o que se tem entendido por educação de qualidade, como a valorização excessiva de testes que medem desempenhos estudantis, que são úteis para elaboração de classificações e ranking. Assim, a autonomia universitária tende a se deslocar das instituições para os órgãos de controle e gestão dos sistemas educacionais. (DIAS SOBRINHO, 2008c, p. 822).

A auto-avaliação que se propõe, levada a efeito pelos próprios agentes que vivem o cotidiano da universidade, deve ter "caráter emancipador". É, portanto, de natureza político-pedagógica,

1 Informações obtidas em http://inep.gov.br/avaliacao-dos-cursos-de-graduacao. 
incorporando uma perspectiva crítico-transformadora como fundamento e uma prática democrática enquanto processo. $\mathrm{O}$ compromisso principal dessa abordagem é o de fazer com que as pessoas direta ou indiretamente envolvidas no processo educativo das instituições de ensino escrevam sua "própria história" e gerem as suas próprias alternativas de ação. (SAUL, 1990, p. 18)

A potencialidade da transformação a partir de uma avaliação participativa está na organização da gestão que busque desenvolver o trabalho, e que, ao superar a centralização e as decisões unilaterais, esteja preocupada em possibilitar as reflexões críticas e a participação democrática.

As características centrais de uma democracia participativa seriam: a formação de uma comunidade política, a autolegislação e a participação constante. Igualmente, a transformação de interesses privados em interesses comuns, a transformação de cidadãos privados e independentes em cidadãos públicos. Para isso, a função primeira da participação seria autoproduzir uma "educação do julgamento (BARBER, 1997:160); uma forma de auto-educação que envolve um processo constante de aprendizagem. (LEITE, 2005, p. 75)

Segundo (PARO, 2008), a gestão democrática requer:

instalação de uma estrutura político-administrativa adequada à participação nas tomadas de decisão de todos os setores que aí têm presença, em especial seus usuários, eivada de mecanismos institucionais que viabilizem e incentivem: processos eletivos para escolha de dirigentes escolares; conselhos de escola formados pelos vários segmentos da unidade escolar e de efetiva função política de direção de escola, grêmio estudantil, associação de pais, professores e funcionários, como fóruns de constante discussão dos múltiplos interesses, bem como outros recursos institucionais que facilitem o permanente acesso de todos os interessados aos assuntos que dizem respeito à vida da escola. (p. 79-80)

A gestão participativa e democrática em grandes instituições educativas tende a se revestir de grande complexidade. A gestão de uma instituição multicampi precisa considerar que "a autonomia precisa ser gerida, implicando uma corresponsabilidade consciente, partilhada, solidária, de todos os membros da equipe escolar" (LIBÂNEO, 2008, p. 142). Em coerência com o conceito de autonomia, a gestão democrática requer vínculos mais estreitos com a comunidade educativa, entidades e organizações paralelas à escola. 
[...] é possível destacar a existência de um esforço dos dirigentes para a institucionalização da gestão democrática e participativa. Este processo se evidencia na escolha dos dirigentes (Reitor, DiretorGeral dos Campi e Coordenadores de Cursos) que se dá por meio de eleições diretas envolvendo os diferentes segmentos da comunidade escolar, ou seja, profissionais da educação (professores e técnicos administrativos) e estudantes. Além dessas escolhas, os Conselhos, Comitês, Núcleos, etc. são constituídos também por meio de eleições. Esses procedimentos são complexos e exigem diplomacia. Trata-se de mecanismos com presença e disputas e requerem maturidade nas relações interpessoais que se estabelecem. (CASTAMAN \& VIEIRA, 2019. p. 42-43)

Sendo assim, é de fundamental importância que, para além dos processos democráticos de escolha dos dirigentes e representantes em conselhos e comissões, haja uma intencionalidade política para implementação de uma gestão participativa a ser exercida por meio da "co-gestão", ou seja, "uma relação de autoridade partilhada" (LEITE, 2005, p. 122).

A organização da gestão de forma participativa é um processo político com propósito coletivo. "Os gestores participativos baseiam-se no conceito da autoridade compartilhada, por meio da qual o poder é dividido com representantes da comunidade escolar local e as responsabilidades são assumidas em conjunto". (LÜCK et al.,2010, p. 21).

Uma gestão democrática pressupõe uma

avaliação compartilhada - Todas as decisões e procedimentos organizativos precisam ser acompanhados e avaliados, com base no princípio da relação orgânica entre a direção e a participação dos membros da equipe escolar. Além disso, é preciso insistir no conjunto das ações de organização do trabalho na escola está voltado para as ações pedagógico-didáticas, em razão dos objetivos básicos da escola. O controle implica uma avaliação mútua entre direção, professores e comunidade" (LIBÂNEO, 2008, p. 146).

Ao direcionar-se para o processo democrático, a equipe entende que "o planejamento participativo, assumido como processo de crescimento e de transformação social, talvez seja o único caminho viável para se conseguir a renovação profunda das estruturas e das relações na educação formal" (DALMAS, 2011 , p. 30). Nesse sentido, Vianna (2000, p. 39) afirma que "genericamente, o Planejamento Participativo constitui-se uma estratégia de trabalho, que se 
caracteriza pela integração de todos os setores da atividade humana social, num processo global, para a solução de problemas comuns."

Ao participar do planejamento "a equipe da escola precisa investir sistematicamente na mudança das relações autoritárias para relações baseadas no diálogo e no consenso" (LIBÂNEO, 2008, p. 146). O Planejamento Participativo com a participação de todos os segmentos, pode trazer à tona os problemas que estavam escondidos, desvelando outras visões do problema, ao mesmo tempo em que ajuda a ganhar a aceitação e o envolvimento dos interessados. "Politicamente, passarão a acompanhar, fiscalizar, assessorar a execução de tarefas comuns. Serão pessoas humanas, ontológica e politicamente participantes, conscientes e críticas." (VIANNA, 2000, p. 42).

Gandin (2013) destaca que o planejamento tem o papel de transformar ideias em processos e deve extrapolar o senso comum, optando por um método científico que tenha a intenção de não apenas de entender a realidade, mas de transformá-la. $\mathrm{O}$ autor defende que o planejamento acontece em quatro passos para dar lucidez e coerência a esse método. São eles:

descobrir os problemas e os desafios da realidade, sobretudo da global; construir um referencial com temas sugeridos pelos desafios; avaliar a prática da entidade à luz daquele referencial; propor uma nova prática para dar conta, em parte pelo menos, dos desafios descobertos (GANDIN, 2013, p. 22)

Dalmás (2011) afirma que o planejamento é formado por um complexo composto pelo Marco Situacional (MS), Marco Doutrinal (MD) e o Marco Operacional (MO). O primeiro é a descrição da realidade que se vive. O MD "é a parte do planejamento que pretende mostrar aonde se quer chegar" (p. 31), representa o devir de pessoa, sociedade e de educação, é nesse momento que a comunidade acadêmica descreve a utopia. O MO "é a tomada de decisões concretas" (p. 31).

Ao realizar um diagnóstico, é o momento de confrontar o que se espera como ideal (MD e MO) com a realidade educativa da escola (MS). Após a identificação dos principais avanços, necessidades, limites é feita a programação, que define o que será possível fazer durante a execução do plano. A avaliação não é uma única etapa, ela permeia todo o processo, por isso a importância da avaliação institucional estar vinculada ao planejamento. 
A avaliação é o motor que assegura o dinamismo do plano, pela constante atualização através de sucessivas revisões e reformulações. Possui duplo aspecto: de controle e de realimentação. Está no todo e em cada parte. A avaliação confronta os resultados alcançados com os resultados desejados (objetivos), para analisar as causas dos acertos ou dos desvios ocorridos. (DALMÁS, 2011, p. 34)

Em função das características apresentadas da metodologia do Planejamento Participativo, justifica-se a necessidade de uma avaliação emancipatória e participativa, onde a participação envolve

o processo de conscientização [que] é a mola mestra de uma pedagogia emancipadora em que os membros de uma organização são tratados como seres autodeterminados, isto é, sujeitos capazes de, criticamente, desenvolverem suas próprias ações. Na abordagem crítica se privilegia o enfoque multidisciplinar que busca a apreensão simultânea e integrada de múltiplas dimensões da instituição. (SAUL, 2010, p. 56)

Em relação à avaliação, ao propor nesta pesquisa uma crítica ao modelo de avaliação dominante, controladora, gerencialista, e uma defesa da participação, conscientização e autocrítica de todos os agentes, adotamos o conceito de avaliação emancipatória, que tem o compromisso com a busca da autocrítica das suas ações e a busca de alternativas para a transformação da realidade. Para tanto, este estudo vale como um alerta para não perder de vista que "a ordem econômica e, seguindo seu modelo, em grande parte também a organização econômica, continuam obrigando a maioria das pessoas a depender de situações dadas em relação às quais são impotentes, bem como a se manter numa situação de não-emancipação" (ADORNO, 2010, p. 43).

Nas palavras do mesmo autor

Numa democracia, quem defende ideais contrários à emancipação, e, portanto, contrários à decisão consciente e independente de cada pessoa em particular, é um antidemocrata, até mesmo se as idéias ${ }^{2}$ que correspondem a seus desígnios são difundidas no plano formal da democracia. As tendências de apresentação de ideais exteriores que não se originam a partir da própria consciência emancipada, ou melhor, que se legitimam frente a essa consciência, permanecem sendo coletivistas-reacionárias. Elas apontam para uma esfera a que deveríamos nos opor não só exteriormente pela política, mas

2 Redação ortográfica conforme original. 
também em outros planos muito mais profundos. (ADORNO, 2010, p. 143)

No sentido de fortalecer a democracia dentro do processo de avaliação, Saul (2010) apresenta o paradigma da Avaliação Emancipatória, que propõe um modelo de avaliação que se oponha ao da racionalidade técnica. A Avaliação Emancipatória caracteriza-se como um processo de descrição, análise e crítica de uma dada realidade, visando transformá-la. A criação desse paradigma foi "inspirada em três vertentes teórico-metodológicas: a primeira delas caracteriza-se como avaliação democrática ${ }^{3}$; a segunda é a crítica institucional e a criação coletiva ${ }^{4}$; e a terceira é a pesquisa participante" (SAUL, 2010, p. 55-56). Todas essas etapas se complementam no sentido de transformação da realidade da instituição.

A avaliação emancipatória caracteriza-se como um processo de descrição, análise e crítica de uma dada realidade, visando transformá-la. Destina-se à avaliação de programas educacionais ou sociais. Ela está situada numa vertente político-pedagógica cujo interesse primordial é emancipador, ou seja, libertador, visando provocar a crítica, de modo a libertar os sujeitos de condicionamentos deterministas. O compromisso principal desta avaliação é o de fazer com que as pessoas direta ou indiretamente envolvidas em uma ação educacional escrevam a sua "própria história" e gerem as suas próprias alternativas de ação. (SAUL, 2010, p. 65)

Nesse sentido, Leite (2005, p. 42) afirma que, "neste formato avaliativo os usuários aprendem a fazer a avaliação junto com os profissionais avaliadores e, por isso, diz-se que a instituição aprende também." Para isso, a participação deve ser reconhecida e estimulada. De acordo com Leite (2005, p. 116), "a sensibilização é

3 Conceito descrito por Barry Macdonald (1977), onde o avaliador age como um intermediário nas trocas de informações entre diferentes grupos. "Os conceitos-chave da avaliação democrática são 'sigilo', 'negociação' e 'acessibilidade'. O conceito fundamental que a justifica é o 'direito à informação' (SAUL, 2010, p.56)."

4 A crítica institucional e criação coletiva concretizam-se através de três momentos ou fases que se articulam num único harmonioso movimento. "Primeiro momento: verbalização e problematização de uma dada realidade, [...] Segundo momento: "Esta etapa caracteriza-se por um recuo crítico que "efetiva-se basicamente pela tomada de consciência, pelo grupo, das distâncias que por vezes existem entre as propostas e as ações de uma organização [...], Terceiro momento: Este momento prevê o delineamento de alterações necessárias no curso da ação em uma organização". (SAUL, 2010, p. 50-60)

5 "É a metodologia que procura incentivar o desenvolvimento autônomo (autoconfiante), a partir das bases de uma relativa independência do exterior". (HUYNH apud SAUL, 2010, p. 63). 
uma fase da Avaliação Participativa que corresponderia ao conjunto de, pelo menos, três pontos do diálogo democrático de Barber (1997): a formulação de interesses dos participantes, a persuasão e o estabelecimento de uma agenda política".

Assim, reforça-se a opção pela avaliação emancipatória na orientação desta pesquisa e pela elaboração de um produto, que articule essa base conceitual com a realidade que vem sendo construída no campus Gravataí. Este estudo visa ser uma prática pedagógica na direção da melhoria da qualidade de ensino, na perspectiva da gestão democrática e participativa e das políticas públicas de avaliação. Investir na avaliação interna é um caminho que pode se revelar potente na transformação da universidade (SAUL, 1990, p. 19) ou, no caso desta pesquisa, nos Institutos Federais.

\section{MATERIAIS E MÉTODOS}

A pesquisa caracteriza-se como qualitativa. Nesse tipo de abordagem "a preocupação do pesquisador não é com a representatividade numérica do grupo pesquisado, mas com o aprofundamento da compreensão de um grupo social, de uma organização, de uma instituição, de uma trajetória, etc". (GOLDEMBERG, 2004, P.14). Nesse artigo apresentamos, além da revisão do referencial teórico, a primeira etapa da pesquisa, que consistiu em análise documental, cuja finalidade consistiu em melhor compreender o contexto da pesquisa. Apresentar o referencial teórico e a análise documental mapeamento de materiais realizado com o propósito de identificar a existência de produtos semelhantes ao proposto na pesquisa, como cartilhas/manuais de avaliação. Para fins da elaboração do quadro comparativo foram escolhidos os seguintes documentos: Guia de Avaliação Institucional da UFES (Universidade Federal do Espírito Santos), Cartilha CPA do IFMG (Instituto Federal de Minas Gerais) e Cartilha orientadora para Elaboração do Relatório de Autoavaliação UFJF (Universidade Federal de Juiz de Fora).

\section{RESULTADOS PARCIAIS E DISCUSSÃO}

O que se verificou, a partir desses referenciais é a que a regulamentação que trata de avaliação, tanto no que tange aos aspectos regulamentados, quando ao 
conteúdo das normas, não atendem as particularidades dos Institutos Federais. Ao mesmo tempo a falta de uma legislação e orientação específica, dificulta o estabelecimento de uma cultura de avaliação. Por outro lado, os referencias teóricos apontam para a necessidade de criar espaços de avaliação e participação para reforçar a relação entre a avaliação institucional e a gestão democrática.

Foram analisados estudos publicados por Universidades e Institutos Federais e os resultados apontam para o avanço no modelo proposto como produto dessa pesquisa em relação às práticas já existentes.

Observando o Quadro 1, é possível perceber que as cartilhas/manuais esclarecem aspectos importantes da avaliação institucional, como questão de regulamentação e funções da CPA. No entanto, se limitam à questões operacionais. Nenhum dos documentos selecionados esclarece questões voltadas para a gestão democrática e sua relação com o planejamento participativo.

Quadro 1 - Análise de produtos já existentes em relação à avaliação institucional e gestão democrática

\begin{tabular}{|c|c|c|c|c|}
\hline CONTEÚDO & $\begin{array}{c}\text { GUIA } \\
\text { DE } \\
\text { AVALIA } \\
\text { ÇÃO } \\
\text { INSTIT } \\
\text { UCIO- } \\
\text { NAL } \\
\text { UFES }\end{array}$ & $\begin{array}{l}\text { CARTILHA } \\
\text { CPA IFMG }\end{array}$ & $\begin{array}{c}\text { CARTILHA } \\
\text { ORIENTADOR } \\
\text { A PARA } \\
\text { ELABORAÇÃO } \\
\text { DO } \\
\text { RELATÓRIO } \\
\text { DE } \\
\text { AUTOAVALIAÇ } \\
\text { ÃO } \\
\text { UFJF }\end{array}$ & $\begin{array}{c}\text { GUIA DE } \\
\text { AVALIAÇÃO } \\
\text { INSTITUCION } \\
\text { AL: } \\
\text { CONTRIBUIÇ } \\
\text { ÕES PARA } \\
\text { UM } \\
\text { PERCURSO } \\
\text { DE GESTÃO } \\
\text { DEMOCRÁTIC } \\
\text { A, } \\
\text { PARTICIPATI } \\
\text { VA E } \\
\text { EDUCACONA } \\
\text { L }\end{array}$ \\
\hline SINAES & $\mathbf{x}$ & $\mathbf{x}$ & $\mathbf{x}$ & $\mathbf{x}$ \\
\hline CPA & $\mathbf{x}$ & $\mathbf{x}$ & $\mathbf{x}$ & $x$ \\
\hline AUTOAVALIAÇÃO & $\mathbf{x}$ & $\mathbf{x}$ & $\mathbf{x}$ & $\mathbf{x}$ \\
\hline REGULAMENTAÇÃO & $\mathbf{x}$ & $\mathbf{x}$ & $\mathbf{x}$ & $\mathbf{x}$ \\
\hline
\end{tabular}




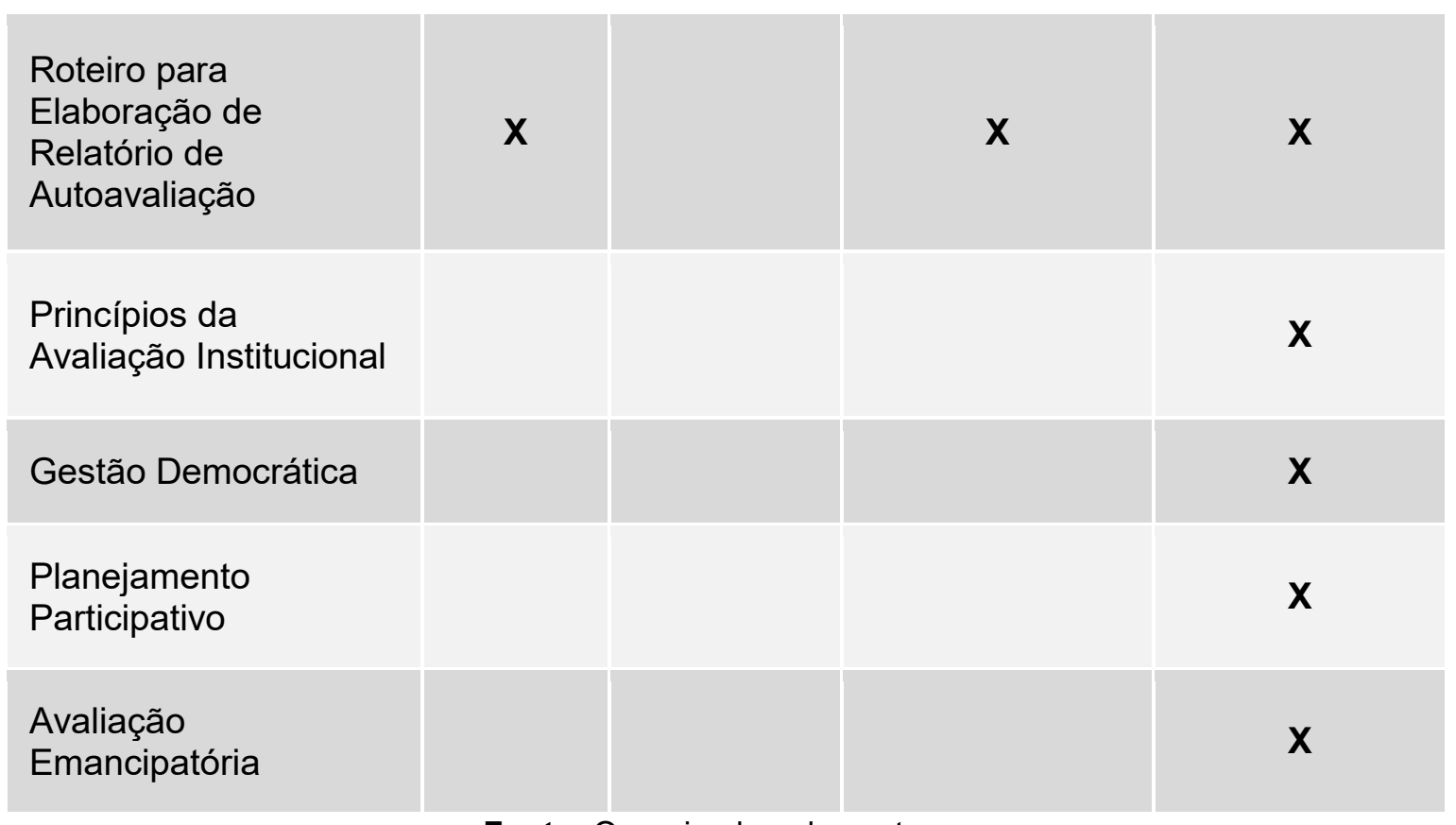

Fonte: Organizado pelas autoras

\section{CONSIDERAÇÕES FINAIS}

Ao olhar o processo de avaliação institucional com mais atenção, reforçamos a importância da melhoria da qualidade da educação oferecida pela Instituição, em todos os níveis e funções. A busca da qualidade deve ter sempre em foco a função social da instituição. Esta pesquisa visa contribuir para a melhoria dos processos de avaliação institucional e de gestão participativa do IFSul e poderá ser usada por outros campi do respectivo instituto, bem como por outros Institutos Federais.

Entendemos que é fundamental investir na produção de pesquisa e na elaboração de um produto educacional que estimule o alinhamento entre avaliação, gestão democrática e planejamento participativo. A conclusão da pesquisa e o desenvolvimento do produto educacional pretende apontar caminhos possíveis para fortalecer a cultura da avaliação Institucional alinhada às particularidades da institucionalidade dos Institutos Federais.

\section{REFERÊNCIAS}

ADORNO, Theodor W. Educação e Emancipação. Rio de Janeiro: Paz e Terra, 1995. 
AMARAL. Alberto. Avaliação e Qualidade do Ensino Superior. As muitas racionalidades da qualidade. Leite, Denise (Org). Avaliação participativa e qualidade: os atores locais em foco. Porto Alegre: Sulina; Porto Alegre: Editora Universitária Metodista IPA, 2009.

BARREYO, Gladys Beatriz. ROTHEN, José Carlos. Para uma história da Avaliação da Educação Superior Brasileira: análise dos documentos do PARU, CNRES, GERES E PAIUB. Campinas/Sorocaba (SP): Avaliação, v.13, p. 131-152, mar. 2008. Disponível em: http://www.scielo.br/scielo.php?pid=S141440772008000100008\&script=sci_abstract\&tlng=pt. Acesso em: 10 de agosto de 2019.

BRASIL. DECRETO No 2.026, de 10 de outubro de 1996. Estabelece procedimentos para o processo e avaliação dos cursos e instituições de ensino superior. Brasília (DF), 1996.

BRASIL. DECRETO N 5.840, de 13 de julho de 2006. Institui, no âmbito federal, o Programa Nacional de Integração da Educação Profissional com a Educação Básica na Modalidade de Educação de Jovens e Adultos - PROEJA e dá outras providências. Brasília (DF), 2006.

BRASIL. LEI No 10.861, de 14 de abril de 2004. Institui o Sistema Nacional de Avaliação da Educação Superior - SINAES - e dá outras Providências. Brasília (DF), 2004.

BRASIL. LEI No 11.892, de 29 de dezembro de 2008. Institui a Rede Federal de Educação Profissional, Científica e Tecnológica, cria os Institutos Federais de Educação, Ciência e Tecnologia, e dá outras providências. Brasília (DF), 2008.

BRASIL. Nota Técnica No 14/CGACGIES/DAES/INEP/MEC. Instrumento de Avaliação Institucional Externa do Sistema Nacional de Avaliação da Educação Superior (SINAES). Brasília: INEP, 2004.

BRASIL. Proposta em Discussão: Políticas Públicas para a Educação Profissional e Tecnológica. Brasília: MEC/SETEC, 2004.

CASTAMAN, Ana Sara. VIEIRA, Josimar de Aparecido. Organização e Gestão Escolar da Educação Profissional e Tecnológica: concepções, princípios e participação. In: CASTAMAN, Ana Sara. VIEIRA, Josimar de Aparecido (Orgs.). Gestão da educação profissional e tecnológica: elementos para reflexão. Curitiba, CRV, 2018.

DALMÁS, Ângelo. Planejamento participativa na escola: elaboração, acompanhamento e avaliação. Petrópolis, RJ: Vozes, 2011.

DIAS SOBRINHO, José. Avaliação e Transformações da Educação Superior Brasileira (1995-2009): do Provão ao SINAES. Avaliação, Campinas; Sorocaba, SP, v.15, n.1, p 195-224, marc. 2010. Disponível em:

http://www.scielo.br/scielo.php?pid=S1414-

40772010000100011\&script=sci_abstract\&tIng=pt. Acesso em: 20 de novembro de 2018. 
DIAS SOBRINHO, José. Avaliação: políticas educacionais e reformas da educação superior. São Paulo: Cortez, 2003.

DIAS SOBRINHOa, José. Avaliação da educação superior: avanços e riscos. Avaliação da educação superior: avanços e riscos. Eccos Revista Científica, vol.10, jul.2008a, p.67-93. Disponível em: http://www.redalyc.org/pdf/715/71509904.pdf. Acesso em: 16 de julho de 2019.

DIAS SOBRINHOb, José. Avaliação Educativa: Produção de sentidos com valor de formação. Avaliação, Campinas; Sorocaba, SP, v.13, n.1, p. 193-207, mar.2008b. Disponível em: http://www.scielo.br/pdf/aval/v13n1/a11v13n1.pdf. Acesso em: 15 de maio de 2019.

DIAS SOBRINHOc, José. Qualidade, Avaliação: do SINAES a Índices. Avaliação: Revista da Avaliação da Educação Superior, vol. 13, n. 3, nov. 2008c, p. 817-825. Universidade de Sorocaba, Sorocaba, Brasil. Disponível em: http://www.scielo.br/scielo.php?script=sci_arttext\&pid=S1414-40772008000300011. Acesso em: 20 de novembro de 2018.

ESCOTT, Clarice Monteiro. Currículos, pedagogia e avaliação em Cursos de Enfermagem e de Direito: influências do discurso regulador geral e do discurso recontextualizador. Tese (doutorado) - Universidade Federal do Rio Grande do Sul. Faculdade de Educação. Programa de Pós-Graduação em Educação, 2008, Porto Alegre, BR-RS.

GANDIN, Danilo. Soluções de Planejamento para uma Prática Estratégica e Participativa. Petrópolis: Vozes, 2013.

GOLDENBERG, Mirian. A arte de pesquisar: como fazer pesquisa qualitativa em Ciências Sociais. Rio de Janeiro: Record, 2004.

Instituto Federal de Educação, Ciência e Tecnologia de Minas Gerais. Cartilha CPA. IFMG: . Comissão Própria de Avaliação 2015-2017. Cartilha CPA. Disponível em: https://www2.ifmg.edu.br/portal/acesso-a-informacao/estrutura/manual-cpa.pdf/view. Acessado em 10 de julho de 2019.

LEITE, Denise. Reformas Universitárias: avaliação institucional participativa. Petrópolis, RJ: Vozes, 2005.

LIBÂNEO, José Carlos. Organização e Gestão da escola: teoria e prática. Goiânia: MF Livros, 2008.

LÜCK, Heloísa; FREITAS, Kátia Siqueira; GIRLING, Robert; KEITH, Sherry. A escola participativa: o trabalho do Gestor Escolar. Petrópolis: Vozes, 2011.

PARO, Vitor Henrique. Gestão Democrática da escola pública. São Paulo: Ática, 2008.

SAUL, Ana Maria. Avaliação da Universidade: buscando uma alternativa 
democrática. Estudos em Avaliação Educacional, São Paulo, n. 1, p. 17-20, 1990. Disponível em: http://publicacoes.fcc.org.br/ojs/index.php/eae/article/view/2403/2351. Acessso em: 15 de julho de 2019.

SAUL, Ana Maria. Avaliação Emancipatória: desafio à teoria e à prática de avaliação e reformulação do currículo. São Paulo: Cortez, 2010.

SOUZA, Nádia Maria Pereira de. O estado da arte da avaliação da educação superior - as diretrizes do MEC e a experiência de IES no Estado do Rio de Janeiro. (Tese de Doutorado). UFRRJ, CPDA, Rio de Janeiro, 2002. Universidade Federal de Juiz de Fora. Cartilha Orientadora para elaboração do relatório de autoavaliação Institucional 2017. UFJF: Diretoria de Avaliação Institucional e Comissão Própria de Avaliação.. Disponível em: http://www.ufjf.br/cpa/files/2017/11/Cartilha_RAAI_2017.pdf. Acessado em 10 de julho de 2019.

Universidade Federal do Espírito Santo. Guia de Avaliação Institucional 2016. UFES: Secretaria de Avaliação Institucional/Comissão Própria de Avaliação. Disponível em: http://avaliacaoinstitucional.ufes.br/sites/avaliacaoinstitucional.ufes.br/files/field/anex o/guia_avaliacao_institucional_2016_ufes_cpa_seavin.pdf. Acessado em 10 de julho de 2019.

VIANNA, Ilca Oliveira de Almeida Vianna. Planejamento participativo na escola: um desafio ao educador. São Paulo: EPU, 2000. 